\title{
EL SOLUTRENSE DEL ABRIGO DE LA VIÑA (ASTURIAS, ESPAÑA). CUALIDADES GENERALES E INDUSTRIA LÍTICA DEL NIVEL VI DEL SECTOR OCCIDENTAL
}

\section{The Solutrean of La Viña rock shelter (Asturias, Spain). General features and lithic industry of the western sector level VI}

\author{
Javier Fernández de la Vega Medina ${ }^{1}$ y Marco de la Rasilla Vives ${ }^{1}$
}

Recibido el 5 de abril de 2013. Aceptado el 10 de julio de 2013

Resumen. En este trabajo se presentarán las caracteristicas generales de las evidencias solutrenses del yacimiento de La Viña (Oviedo, Asturias, España); así como un análisis tecno-tipológico preliminar de la colección lítica del nivel VI a fin de contribuir al conocimiento del desarrollo regional del Solutrense medio. La metodología aplicada al estudio utiliza las listas tipológicas y los estudios tecnológicos al uso ampliándose, en el último caso, las variables según la propuesta de D. Santamaría.

Palabras clave: Solutrense, región cantábrica, industria lítica, tecnología, tipología, La Viña, Asturias.

Abstract. We present the main features of the Solutrean evidences of La Viña rock shelter (Oviedo, Asturias, Spain), as well as a preliminary typo-technological analysis of the level VI lithic collection allowing us to know the middle Solutrean regional development. The methodology employed in this study use the common typological lists and the technological studies increasing the last one with more variables according D. Santamaría proposal.

Key words: Solutrean, cantabrian region, lithic industry, technology, typology, La Viña, Asturias.

\section{INTRODUCCIÓN}

El abrigo de La Viña se encuentra en La Manzaneda, localidad situada a siete kilómetros de la ciudad de Oviedo (España). Con una orientación sur-sureste y más de treinta metros de frente, el abrigo se abre a unos cien metros de altura sobre la margen derecha del río Nalón. Una antigua visera natural, hoy colapsada, y su situación preponderante sobre el curso medio del mencionado río, convierten sin duda a este yacimiento en un lugar privilegiado para la habi- tación humana (Fortea 1990). Así lo confirma su importante secuencia estratigráfica.

Descubierto su interés arqueológico en 1976, se iniciaría su excavación sistemática en 1980 bajo la dirección de Javier Fortea Pérez. Estos trabajos se prolongarian hasta el año 1998. A lo largo de estas campañas la intervención arqueológica alcanzó una extensión de más de 40 metros cuadrados, repartidos en dos sectores: central y occidental (Fig. 1). Por su parte, la profundidad máxima excavada superaría los 3 metros en la banda 14 del sector central y en

(') Área de Prehistoria. Departamento de Historia. Facultad de Filosofia y Letras. Universidad de Oviedo. Calle Teniente Alfonso Martínez s/n. E-33011 Oviedo (España). 


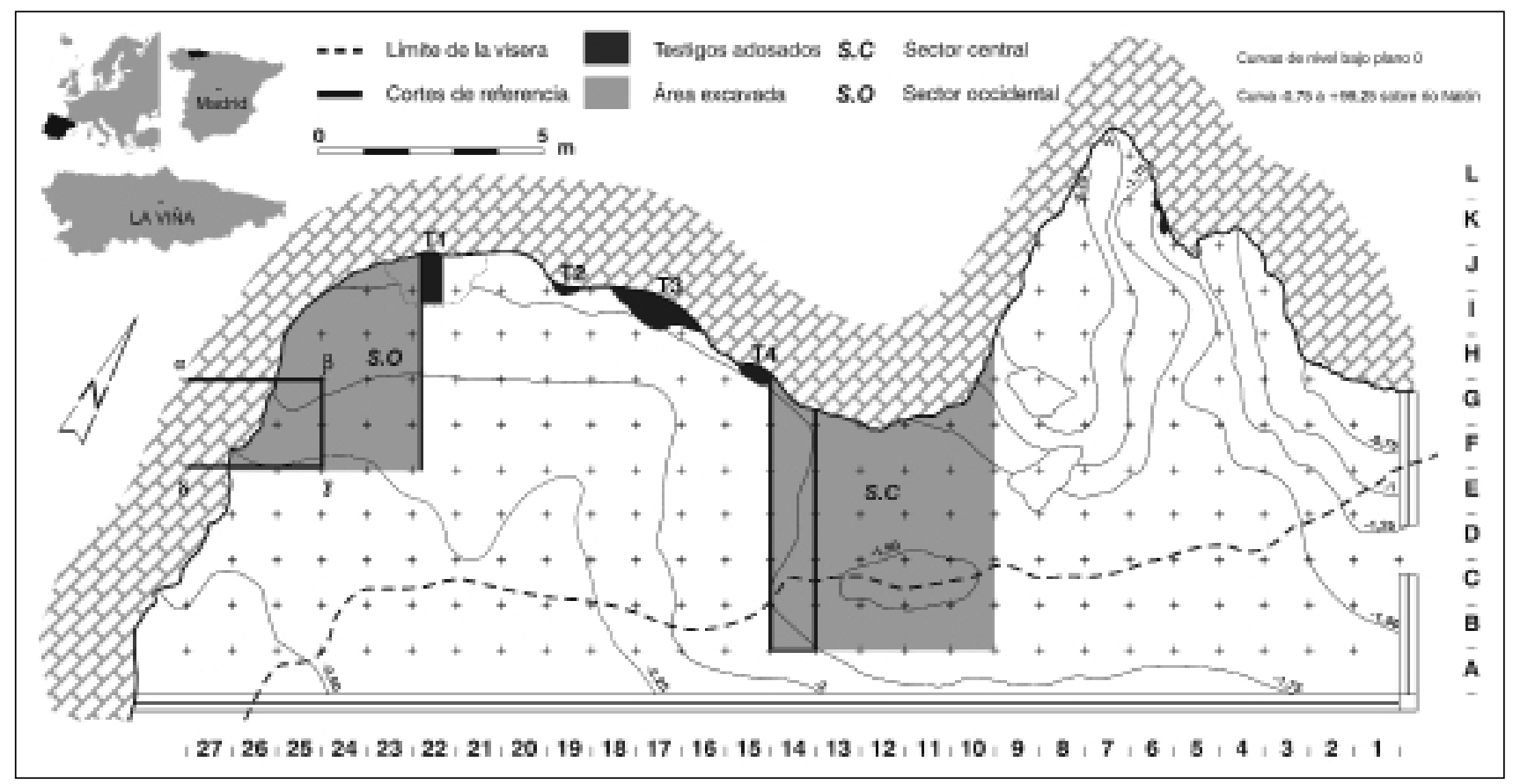

\ Figura 1. Planta y sectores del Abrigo de La Viña.

las bandas $\mathrm{G}$ y $\mathrm{F}$ del sector occidental (Fortea 1990, 1992, 1995 y 1999).

El gran abrigo de La Viña posee una larga estratigrafía que contiene numerosos niveles que abarcan todos los tecno-complejos del Paleolítico superior del occidente de Europa, desde el Protoauriñaciense/Auriñaciense arcaico al Magdaleniense superior. La identificación cultural del Solutrense en La Viña se relaciona en el sector central con los niveles $V$ y Vla (Fig. 2), mientras que en el sector occidental se caracteriza en los niveles $\mathrm{V}$ y VI (Fig. 3).
Según Fortea (1990), en ambos sectores el nivel $V$ se correspondería con un Solutrense superior y el nivel VI con un Solutrense medio.

De acuerdo con el estudio sedimentológico de M. Hoyos, en el sector central el nivel V (Solutrense superior) se presenta dividido en diferentes facies según cuadros: de esta manera se distingue $\mathrm{Va}$, amarillo, con abundante matriz fina y pocos cantos en los cuadros de F a B-14; Va1, negro, de vertido de hogar, se sitúa hacia el centro de $F-14 ; \mathrm{Vb}$ y $\mathrm{Vb} 1$ son dos subdivisiones de una misma unidad, cuya facies es la

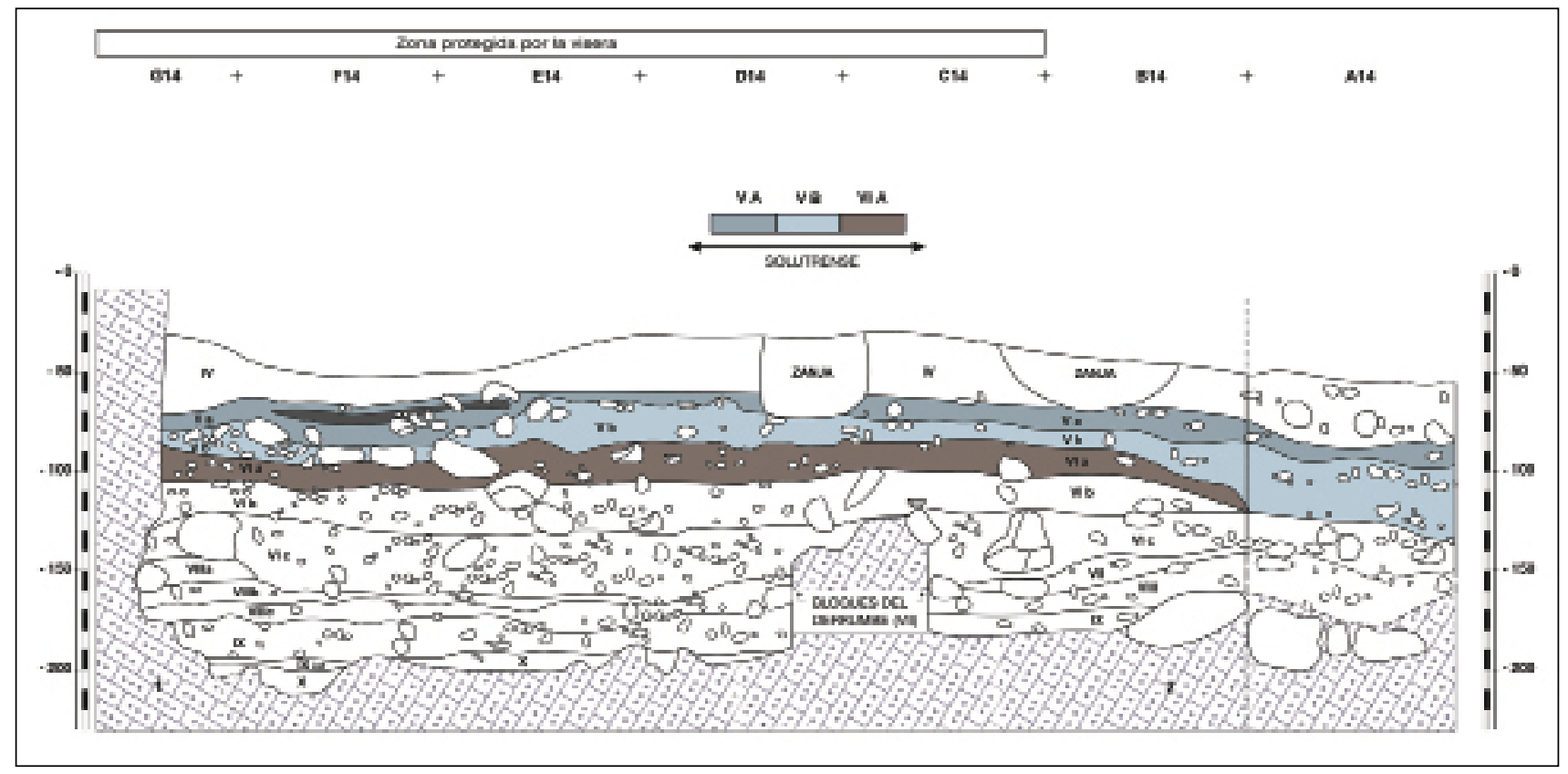

- Figura 2. Corte y secuencia estratigráfica del sector central del Abrigo de La Viña. En color los niveles solutrenses. 


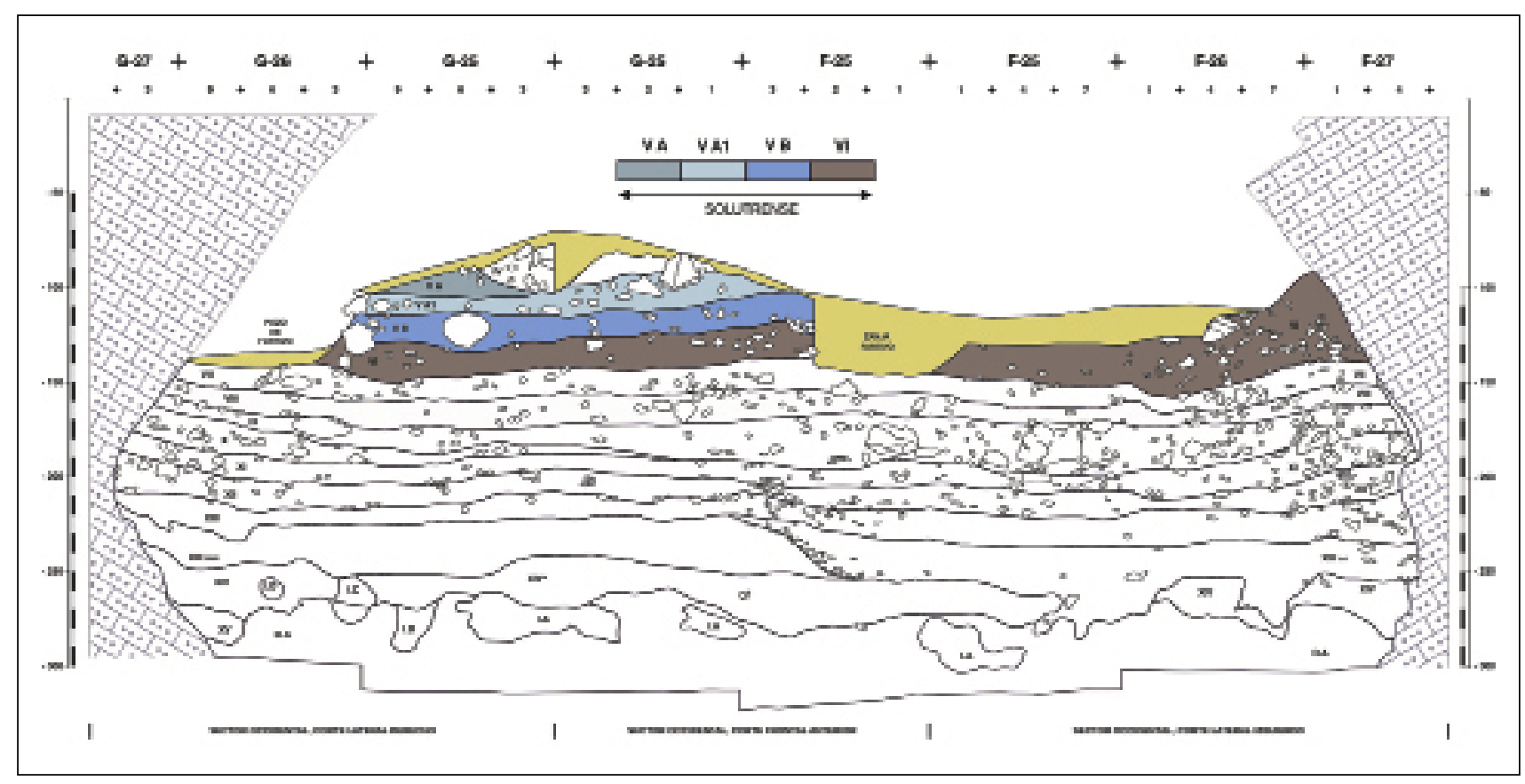

ム Figura 3. Corte y secuencia estratigráfica del sector occidental del Abrigo de La Viña. En color los niveles solutrenses. Obsérvese que el corte está desplegado para su mejor visualización.

de pequeños cantos lavados y prácticamente sin matriz que, en algunas zonas, se ordenan según talla: más gruesos abajo (Vb1) y más pequeños arriba (Vb). Se extiende por la banda 14 desde F-14 a B-14, salvo hacia la mitad de D-14 donde en una franja de unos $60 \mathrm{~cm}$ de anchura se sitúa una zanja rellenada, fruto seguramente del uso agrícola del abrigo en el pasado. Es en C-14 y B-14 donde el nivel V, especialmente el nivel $\mathrm{Vb}$ menos se ve afectado por la acción erosiva, presentándose sin pérdida de matriz (Fortea 1990, 1992).

El nivel VI se presenta en este sector central con matriz arcillosa, amarillenta, muy compacta y penosa de excavar. Es de gran espesor y su diferenciación según color, textura y fracción gruesa se hace muy difícil. Únicamente en su tercio inferior aparece con un mayor componente arenoso, tendiendo su matriz a un color pardo-rojizo. Se divide en Vla, Vlb y Vlc, correspondiendo Vlc a la apreciación sedimentaria aludida y siendo Vla el nivel atribuido a Solutrense medio (Fortea 1990, 1992).

En relación con el sector occidental, éste ofrece un estrato $\mathrm{V}$ muy similar al del sector central aunque conserva toda su matriz, de manera que, afortunadamente, no se observan los lavados laterales en profundidad que motivaron su pérdida en parte del $V$ central (Fortea 1990, 1992). El nivel $\mathrm{VI}$ presenta en este sector un sedimento arcilloso de coloración pardo-grisácea que engloba cantos de caliza dispersos y muy alterados. Hasta la base predominan los restos óseos, materia orgánica y cantos recubiertos de fosfatos. La estratificación es aquí masiva pero presenta un aspecto mucho más poroso y suelto que en el nivel precedente (Fortea 1990, 1992). No obstante, como veremos, tampoco aquí la excavación está exenta de problemática.
En lo que hace a la identificación cultural de los niveles, en el sector central el estrato $V$ se caracteriza por la presencia de las habituales puntas de muesca y de base cóncava; mientras que el grueso paquete VI se mostró bastante pobre en elementos diagnósticos, no asi en materia prima tallada. Puede sin embargo afirmarse que su tramo superior (nivel Vla), que Fortea (1990) lo asocia Solutrense medio de Las Caldas (Corchón 1981), ofrece algunas hojas de laurel y la ausencia de elementos normalmente presentes en el Solutrense superior.

En el sector occidental el estrato $V$ se configura nuevamente en el ámbito Solutrense superior con las mencionadas puntas de base cóncava y de muesca. El nivel VI, esta vez enteramente asociado al Solutrense, presenta también aquí la misma pérdida de tipos característicos del estadio superior; de modo que nos encontramos ante un Solutrense medio con numerosas hojas de laurel en relación a la superficie excavada. Aparecen éstas talladas tanto en sílex, como en cuarcita e incluso alguna en cuarzo hialino de altísima perfección técnica (Fortea 1990, 1992).

El proceso de excavación de este yacimiento (19801998) coincidió con el auge del debate sobre la evolución del Solutrense en la Península Ibérica, pero el ingente volumen de piezas, recuperadas protocolariamente, no pudo someterse en su momento a un análisis exhaustivo. Por ello desde finales del año 2011 ha comenzado a desarrollarse un estudio en profundidad de las miles de piezas de los niveles solutrenses, comprendiendo el análisis completo de sus cadenas operativas, desde la captación de las materias primas hasta la transformación de los soportes en útiles y su posterior uso. En su momento, los resultados de este análisis se integrarán en el marco regional, y se pondrán en relación 
con otros yacimientos similares del territorio peninsular y del ámbito europeo occidental.

Respecto al estudio de la industria lítica se han analizado, entre otras, variables como materia prima, tipometría, accidentes de talla, alteraciones, fracturas, morfología del talón y el retoque. A toda esta información hay que añadir la adscripción tipológica de los materiales, que en el caso que nos ocupa se realiza según la lista de Sonneville-Bordes y Perrot (1954, 1955, 1956a, 1956b), siendo necesaria, por tanto, la evaluación crítica de los índices técnicos y tipológicos utilizados por los autores para ver el comportamiento de los yacimientos asturianos respecto a las series solutrenses hispanas y europeas.

\section{EL SECTOR OCCIDENTAL DE LA VIÑA}

El presente estudio centra su actividad en el análisis del utillaje solutrense extraído del nivel VI del sector occidental de La Viña. El material que nos ocupa fue recuperado en sucesivas campañas entre los años 1985 y 1990, y abarca una extensión variable en la banda de $F$ (cuadros de 23 a 27) y en los cuadros G 25 y 26. El proceso de excavación seguido en este sector, y los lugares elegidos en el planteamiento del mismo, respondieron desde el primer momento a la presencia de dos zonas, conectadas entre sí, en que se detectaba una fuerte alteración del yacimiento. Esas zonas, relacionadas tanto con la actividad ganadera como con una actividad arqueológica furtiva, fueron denominadas pozo y zanja. La zanja, extendida a lo largo de la banda $F$, y el pozo, abarcando los cuadros $F$ y $G$ 25, 26 y 27, fueron vaciados del depósito revuelto hasta dejarlo en zona intacta (Fig. 4).

En profundidad fueron los niveles de IV a VI quienes sufrieron en su mayor parte las consecuencias de pozo y zanja de manera que, la primera labor a que hubo de enfrentarse este estudio fue la de caracterizar con precisión la extensión del daño, el análisis crítico del trabajo excavador realizado, difícil de por sí en estos casos, y la valoración del material recuperado para, con ello, determinar su procedencia exacta. Todo ello permite, cuando ésta es segura, abordar su análisis, o postergarlo si la procedencia ofrece dudas.

Resulta complicado determinar a priori el efecto de pozo y zanja en el yacimiento. Su extensión, forma y profundidad, como corresponde a una labor de excavación clandestina y no reglada es totalmente incoherente. La lectura de los diarios de excavación y de los diarios de trabajo del propio Fortea, así como el análisis de los planos y plantas, ayuda en gran medida a determinar el área, pero resultan en ocasiones inconexos y plantean dudas sobre los límites exactos en algunos puntos. Es necesario precisar que el inventariado de las piezas rige su contenido, orden y adscripción en lo determinado en los diarios de excavación, de manera tal que el conocimiento exacto del diario y su interpretación se hace determinante para valorar la corrección del inventario o, en su caso, para tomar las decisiones oportunas respecto al mismo.

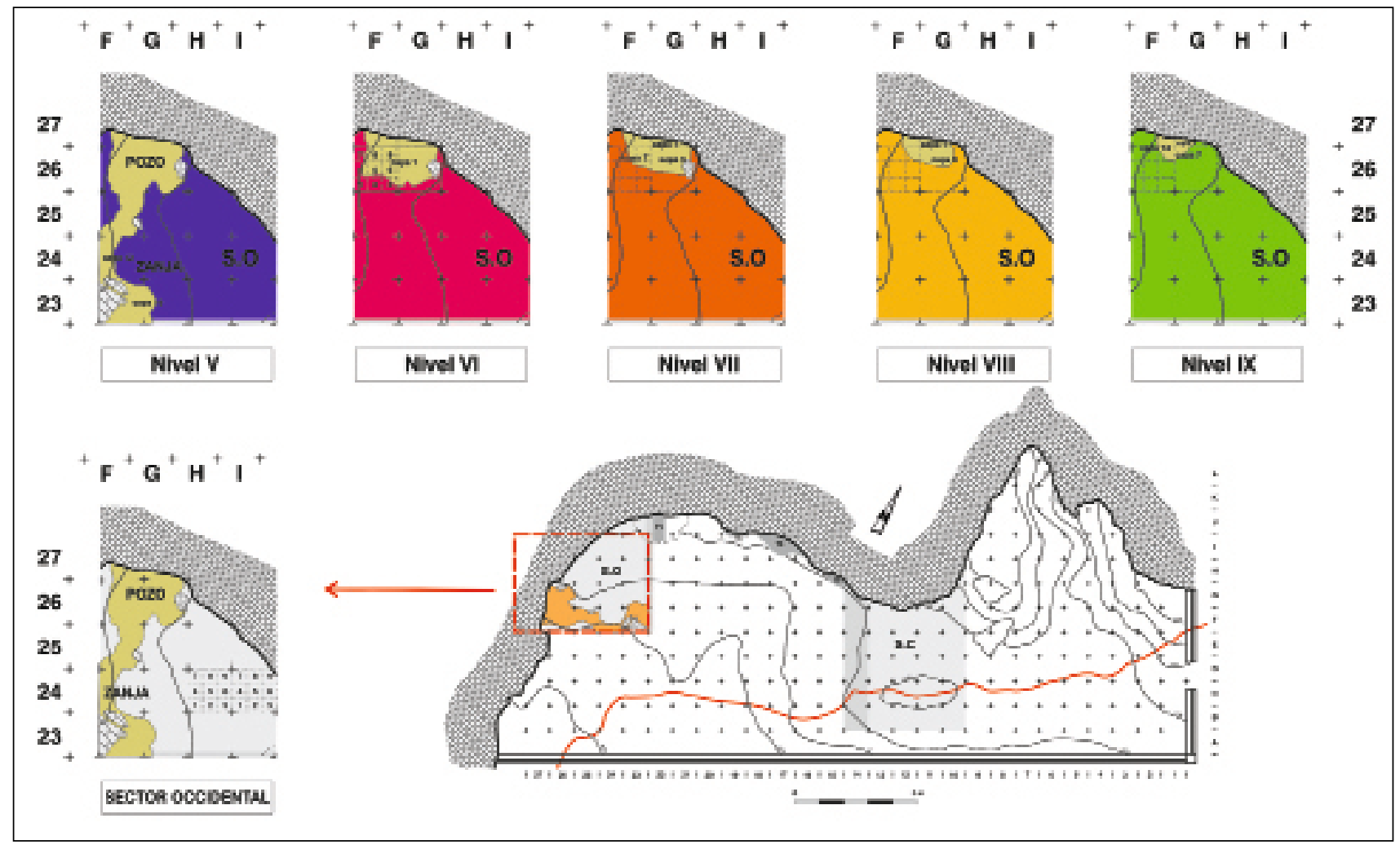

\ Figura 4. Cuadros, subcuadros, capas y niveles afectados por la zanja y el pozo en el sector occidental del Abrigo de La Viña. Dibujo J. Fernández de la Vega. 


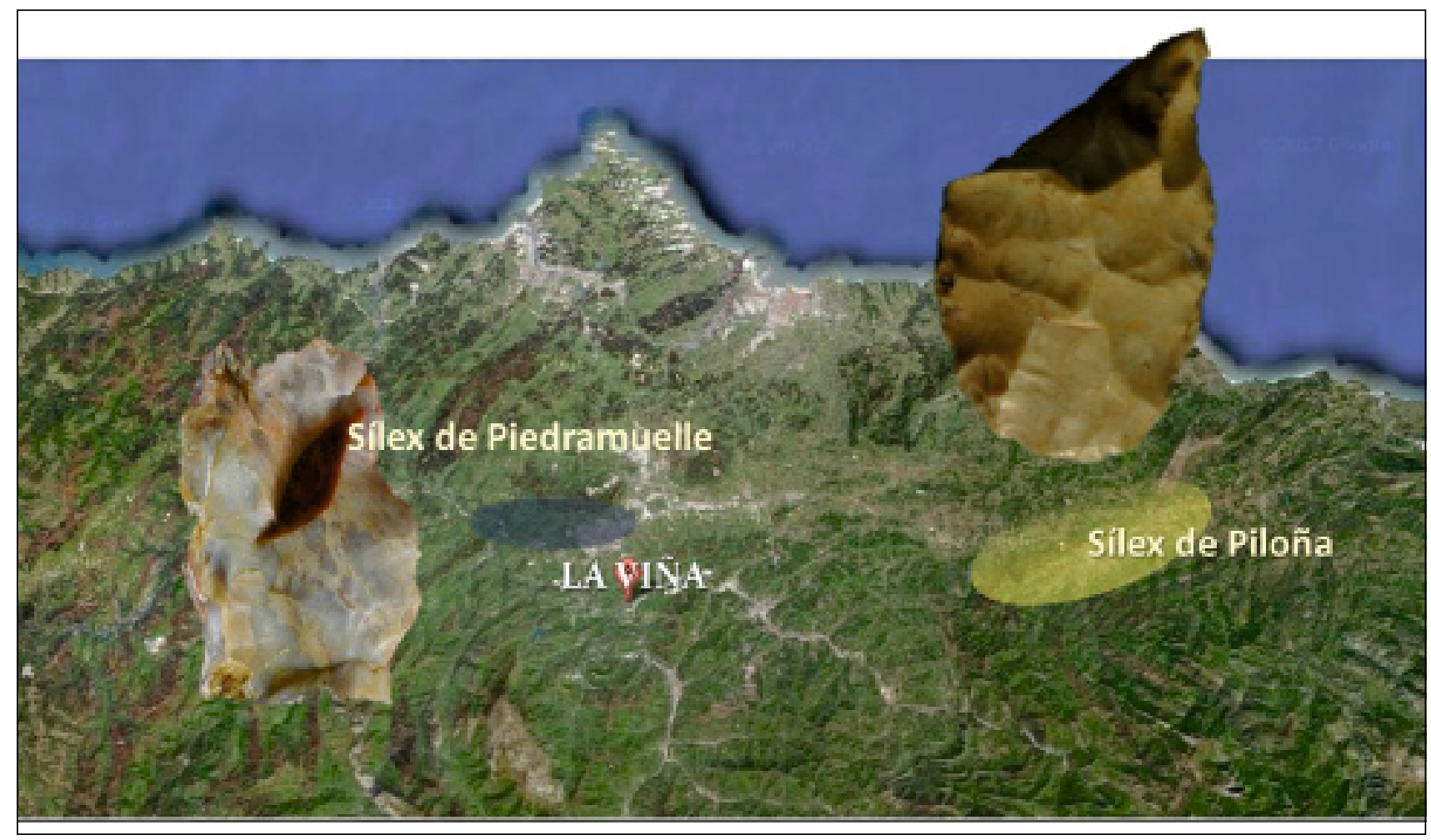

A FiguRA 5. Localización de la zona de captación de los sílex de Piedramuelle y de Piloña, respectivamente a $<7 \mathrm{~km} \mathrm{y} \mathrm{a} \pm 30-40 \mathrm{~km}$. Señalado en el mapa el Abrigo de La Viña.

Partiendo de la planta dibujada en 1989, señalando la extensión de pozo y zanja, se comenzó el proceso de digitalización de las áreas problemáticas y su estudio en correlación a los cortes de referencia (Santamaría et al. 2010; Fortea et al. 2010). Tuvo que ser el estudio pormenorizado y detallado de cada capa de excavación, redactada en los diarios, la que ayudara definitivamente a reconstruir con un grado alto de fiabilidad la extensión y límites de las áreas proyectadas. De esta manera, a partir de las descripciones y dibujos en planta, fueron reconstruidos verticalmente nuevos cortes con los que implementar las referencias existentes y dotar de la mayor exactitud $y$, en consecuencia, fiabilidad, a las descripciones de estos cuadros (Fig. 4).

Apreciamos claramente cómo pozo y zanja afectan en principio a la práctica totalidad del área excavada, si bien en profundidad varian sus límites. Los niveles IV y $\mathrm{V}$ se presentan afectados con una mayor intensidad que ningún otro, estando totalmente destruidos por el pozo y altamente perjudicados en la zona zanja. El nivel VI, quien centra el análisis de este estudio, se presenta intacto en zanja y debe ser en el pozo donde se analice con especial cuidado.

A la vista del plano señalaremos ya que el material del nivel $\mathrm{VI}$ que analizamos provendrá de los cuadros $\mathrm{F}-24, \mathrm{~F}-25$ y G-25 pues no presentan mayores problemas, y corresponderá a los útiles identificados $(\mathrm{N}=182)$. Dejamos para posteriores trabajos el estudio del material de los subcuadros más orientales de F-26 y G-26, así como los subcuadros meridionales de $\mathrm{F}-26$ y F-27, para discernir con todo detalle los que pueden pertenecer al Solutrense de los que están revueltos o son de procedencia dudosa.

\section{ESTUDIO DE LA INDUSTRIA LITICA RETOCADA DEL NIVEL VI}

\subsection{Materia prima}

Contamos, como viene siendo habitual en otros niveles y tecno-complejos del yacimiento (Martínez 2010; Santamaria 2012; Suárez e. p.; Duarte, com. pers.), con varias materias primas entre las que destacan diferentes tipos de silex y cuartita $y$, en mucha menor cuantía, otras como el jaspe, la radiolarita, el cuarzo, el cristal de roca o la arenisca.

A diferencia de la cuarcita, en cuyo estudio se trabaja actualmente en el área de Prehistoria de la Universidad de Oviedo, el conocimiento de los recursos siliceos ha progresado en los últimos años destacando el ya conocido sílex de Piedramuelle que se encuentra en otras estaciones del valle medio del Nalón como Las Caldas o La Lluera (Corchón 1992; Fortea et al. 2009, 2010; Duarte et al. e. p.). Asimismo, en los últimos años se ha incorporado al catálogo el llamado silex de Piloña (Fortea et al. 2009, 2010; Santamaría et al. 2010, 2011; Santamaría 2006, 2012; Duarte et al. e. p.; Tarriño et al. 2012) que, a diferencia del anterior, responde en general mejor a la talla y es el más "viajero" de los sílex asturianos (Fig. 5). 


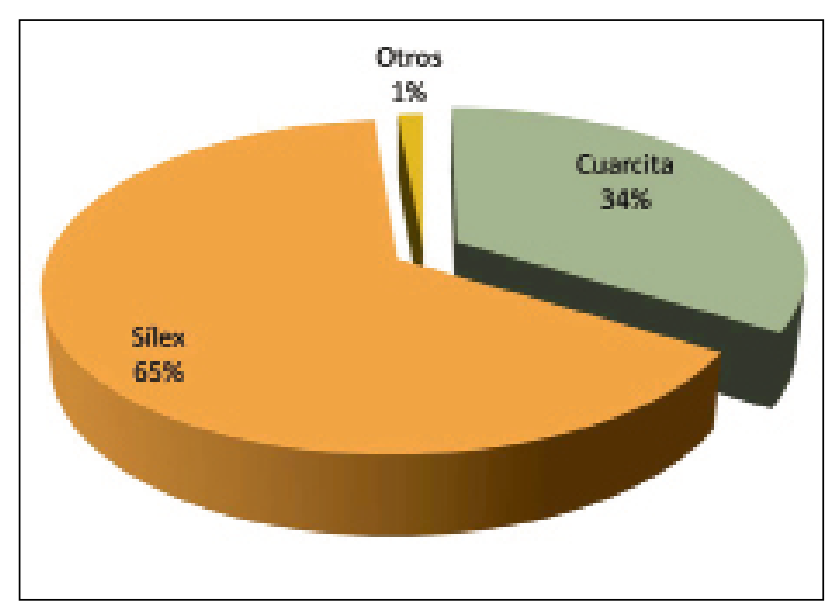

A FiguRa 6. Distribución de las principales materias primas utilizadas en la fabricación de los útiles.

En la colección lítica solutrense de La Viña la desilificación de los sílex impide la identificación de su variedad específica incrementando considerablemente el apartado de los sílex indeterminados; de modo que futuras investigaciones sobre las características de las desilificaciones en esos tipos de sílex permitirán ajustar su adscripción y, entonces, aumentará el número de efectivos principalmente en las variedades de Piedramuelle y Piloña.

El análisis estadístico de las materias primas utilizadas en la colección lítica del nivel VI muestra una significativa superioridad del sílex (65\%) frente a la cuarcita (34\%). Por su parte, el reparto de las variedades de sílex en relación con el total muestra una mayor frecuencia del sílex de Piloña (28\%), quedando en segundo término el sílex de Piedramuelle (14\%) (Figs. 6 y 7).

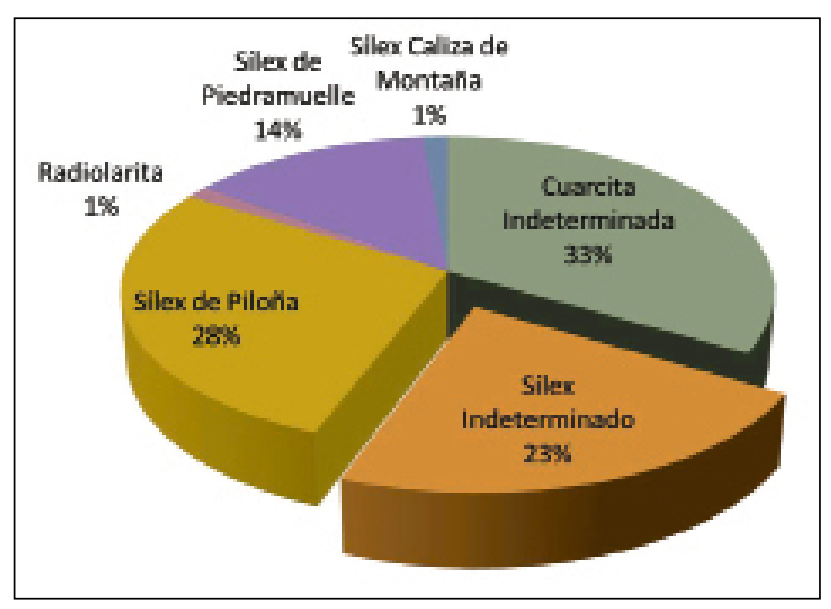

$\Delta$ Figura 7. Frecuencia de la cuarcita y de los principales tipos de sílex definidos.

Este hecho debe tomarse con cautela a la espera del estudio completo de la industria lítica del nivel y a la revisión de los sílex indeterminados (23\%), porque lo normal es que la variedad Piedramuelle sea la dominante debido a la proximidad de los afloramientos al yacimiento. Con todo, aunque el porcentaje de seguridad es, de momento, insuficiente para su clasificación categórica, se observa cómo dentro del conjunto de sílex indeterminado el número de piezas que apunta a un origen Piedramuelle es significativamente mayor que el que haría lo propio en el conjunto de Piloña.

Frente a los materiales silíceos y las cuarcitas, el empleo de otros recursos líticos es señaladamente reducido (2,3\%), estando presentes algunos ejemplos confeccionados en are-

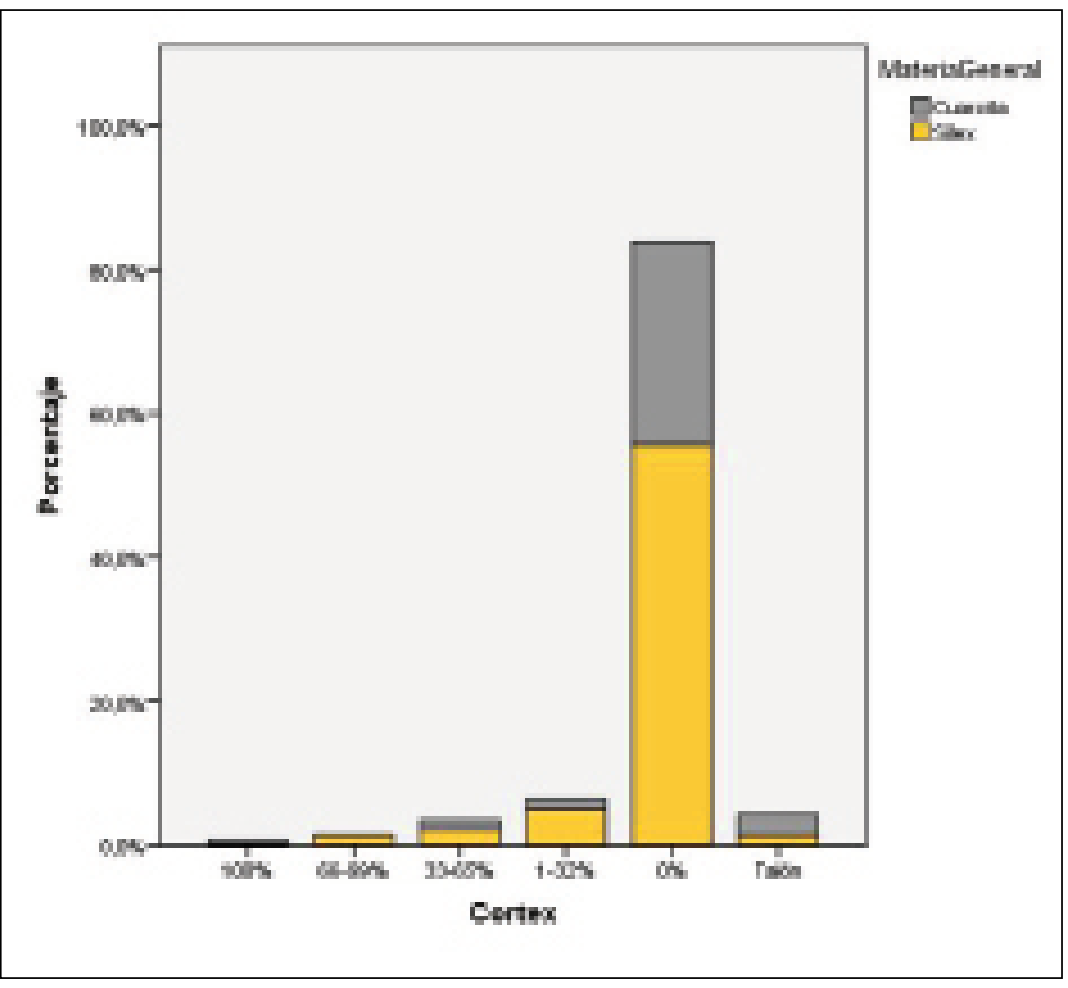

FiguRA 8. Distribución del córtex por materia prima. 


\begin{tabular}{|l|c|c|c|c|}
\hline \multicolumn{1}{|c|}{$\begin{array}{c}\text { TIPO } \\
\text { DE SOPORTE }\end{array}$} & $\begin{array}{c}\text { CUARCITA } \\
\text { INDETERMINADA }\end{array}$ & SÍLEX PILOÑA & SÍLEX PIEDRAMUELLE & SíLEX INDETERMINADO \\
\hline Lasca & $66,0 \%$ & $47,0 \%$ & $66,5 \%$ & $41,5 \%$ \\
\hline Lasca inferior a $25 \mathrm{~mm}$ & $8,5 \%$ & $2,5 \%$ & $0 \%$ & $3,5 \%$ \\
\hline Lámina & $25,5 \%$ & $40,5 \%$ & $28 \%$ & $45 \%$ \\
\hline Laminilla & $0,0 \%$ & $10,0 \%$ & $5,5 \%$ & $10 \%$ \\
\hline
\end{tabular}

A TABla 1. Porcentaje de los tipos de soporte por materia prima. Téngase en cuenta que, con toda probabilidad, bastantes restos indeterminados deberán adscribirse a la variedad Piedramuelle.

nisca, una magnifica punta solutrense en cristal de roca, dos piezas en cuarzo, y varios ejemplares en radiolarita (1\%) y en silex caliza de montaña $(0,9 \%)$.

En relación con el córtex presente en las piezas (Índice de corticalidad: primer orden: 100\%-66\% de córtex; segundo orden: $33-65 \%$ de córtex; tercer orden: 0-32\% de córtex), se constata para las materias primas principales un claro dominio de los útiles realizados sobre soportes de tercer orden (80\%) (Fig. 8).

\subsection{Descripción de los soportes retocados}

Se utilizan preferentemente las lascas o las lascas laminares $(59,4 \%)$ para su transformación en útiles, representando las láminas y laminillas el 39\% de los soportes. Por su parte, es testimonial el aprovechamiento de fragmentos diaclásicos y soportes naturales (Fig. 9).

Respecto a los tipos de soporte por materia prima el comportamiento es similar a lo conocido (Tab. 1): los soportes tipo lasca son más abundantes en cuarcita; pero en el sílex la diferencia no es tan nítida y si se atiende a las variedades silíceas se observa un ligero predominio de la laminaridad en el silex de Piloña y una distribución más proporcionada en los silex de Piedramuelle y en los indeterminados.

La sistematización de los soportes por subtipos (Santamaría 2012), independientemente de su materia prima, muestra una selección preeminente de los cortantes frente a otros modelos para ser retocados (Tab. 2).

El estudio tipométrico del material analizado considerará la longitud, anchura y espesor según la materia prima y el tipo de soporte, y se calcularán los índices de alargamiento y carenado. Tanto en longitud y anchura como en espesor se observan diferencias significativas entre las distintas materias primas, de manera que el tamaño medio de las piezas es claramente superior en cuarcita, donde las medias de las tres medidas casi duplican a las de silex. Es pues plausible pensar en una acentuada incidencia del tipo de materia prima sobre las dimensiones de los soportes, pudiendo incluso haber influido en su selección para la elaboración de útiles (Fig. 10).

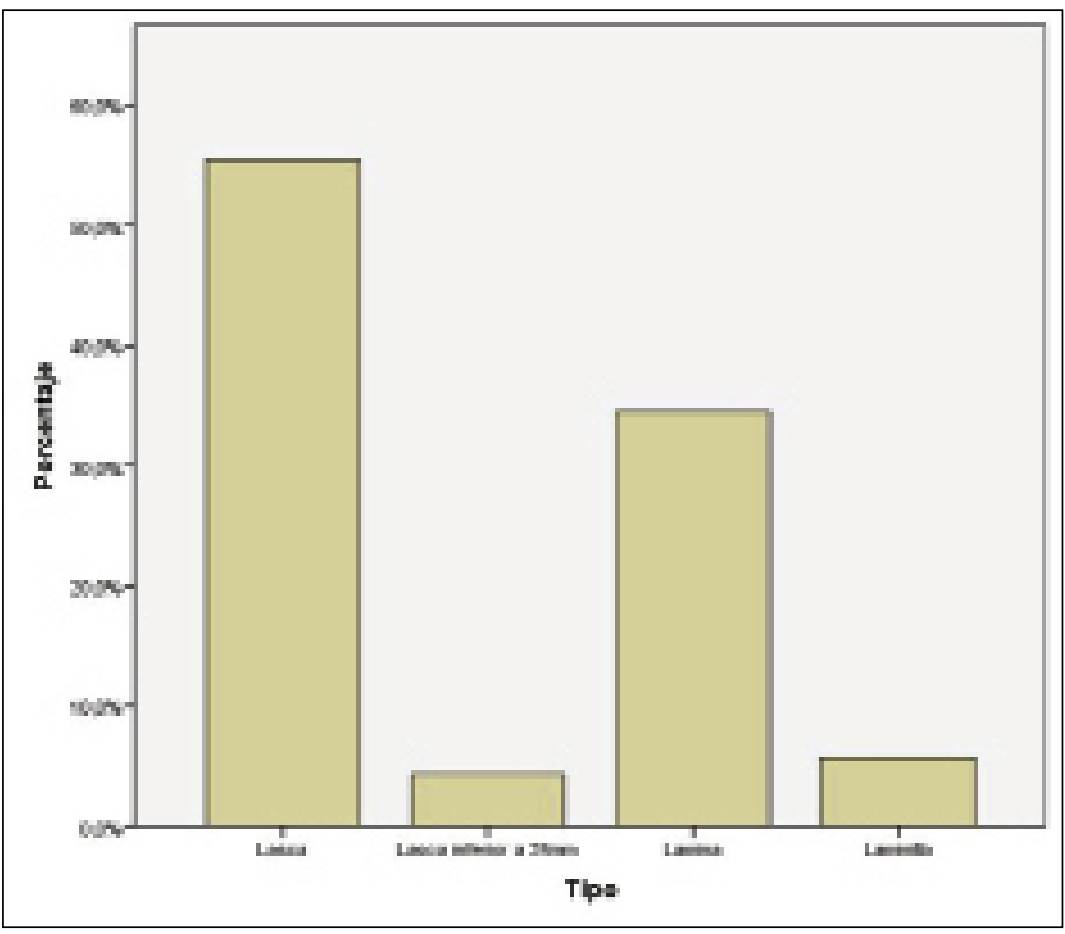

Figura 9. Frecuencia de los soportes con los que se confeccionaron los útiles. 


\begin{tabular}{|c|c|c|c|}
\hline SUBTIPO & GENERAL & CUARCITA & SÍLEX \\
\hline Cortantes & $79,2 \%$ & $77 \%$ & $81,9 \%$ \\
\hline Desbordantes & $9 \%$ & $12,5 \%$ & $7,5 \%$ \\
\hline F. Indeterminado & $8,3 \%$ & $4,3 \%$ & $8,5 \%$ \\
\hline L. Inferior a $25 \mathrm{~mm}$ & $3,5 \%$ & $6,2 \%$ & $2,1 \%$ \\
\hline
\end{tabular}

A TABLA 2. Porcentaje de los subtipos de soporte por materia prima.
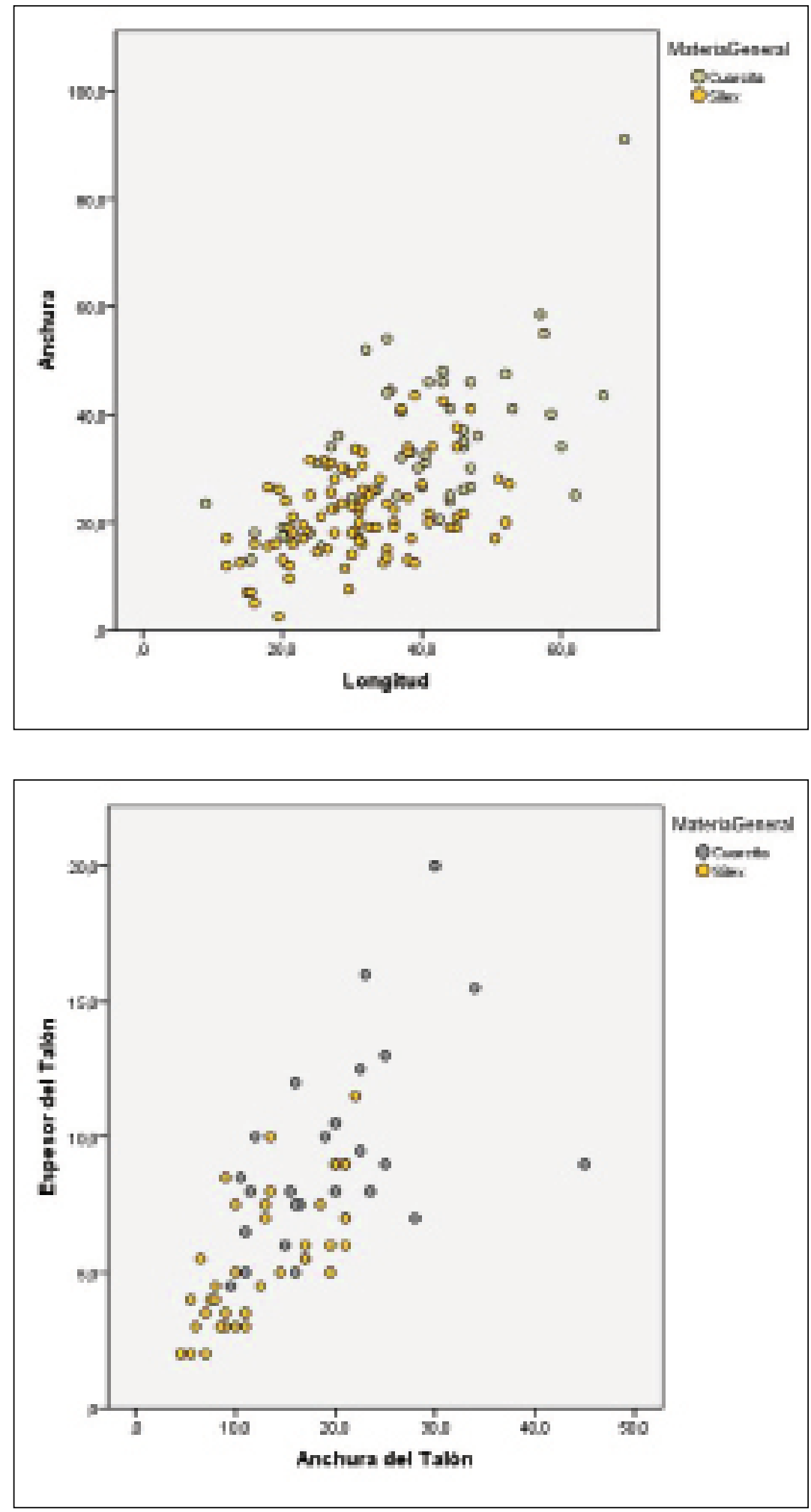

Figura 10. Diagrama de dispersión de las piezas retocadas según su longitud y anchura y tipo de materia prima general empleada.
4 Figura 11. Diagrama de dispersión de los talones completos según su anchura y espesor y tipo de materia prima general empleada. 
Por lo que afecta a la morfología y tipometría de los talones (Tab. 3 y Fig. 11), que genéricamente tienen un ángulo $\geq 90^{\circ}$ respecto a la cara dorsal, se documenta una notable superioridad de los talones lisos (26,6\%), seguidos por los talones suprimidos (13,3\%), mientras el resto se distribuye entre talones rotos, corticales, diedros, facetados y puntiformes. Asimismo, aunque los talones lisos dominan en cualquier tipo de soporte, es pertinente destacar la relativa importancia de la supresión voluntaria de los talones en las láminas. Por su parte, si analizamos los talones según su anchura, espesor y materia prima observamos la preponderancia de los talones estrechos y finos claramente asociados a los soportes en silex cuyos talones, además, son de menor tamaño que los de cuarcita.

El análisis de las fracturas manifiesta un alto porcentaje de fracturación, dado que las piezas completas o con fractura marginal representan el $49,2 \%$ de las piezas, y el resto son soportes fracturados.

La tabla 4 muestra la distribución de las fracturas $y$, también, el tipo de fractura por materia prima, constatándose el predominio de las transversales (40,9\%), seguidas de lejos por las longitudinales transversales $(10,8 \%)$ y las longitudinales (2,9\%). Por otro lado, el índice de fracturación es análogo entre el sílex y la cuarcita (50\% y 49\% respecti-

\begin{tabular}{|l|c|c|c|}
\hline \multicolumn{1}{|c|}{ MORFOLOGÍA DEL TALÓN } & GENERAL & LASCA & LÁMINA \\
\hline Ausente (fractura) & $42,7 \%$ & $35 \%$ & $48 \%$ \\
\hline Cortical & $4,2 \%$ & $6,5 \%$ & $2,1 \%$ \\
\hline Diedro & $2,1 \%$ & $2,6 \%$ & $2 \%$ \\
\hline Facetado & $4,9 \%$ & $6 \%$ & $0 \%$ \\
\hline Liso & $26,6 \%$ & $35 \%$ & $20,7 \%$ \\
\hline Puntiformes & $1 \%$ & $0 \%$ & $0 \%$ \\
\hline Roto/parcialmente roto & $3,5 \%$ & $4,5 \%$ & $6,4 \%$ \\
\hline Suprimido/parcialmente suprimido & $13,3 \%$ & $10,4 \%$ & $20,8 \%$ \\
\hline
\end{tabular}

\ Tabla 3. Porcentaje de los tipos de talón y frecuencia por soporte de los talones mayoritarios.

\begin{tabular}{|c|c|c|}
\hline TIPO DE FRACTURA & CUARCITA & SÍLEX \\
\hline Completa & $34,7 \%$ & $30,9 \%$ \\
\hline F. Indeterminado & $2,7 \%$ & $3,2 \%$ \\
\hline Longitudinal derecha & - & $2,5 \%$ \\
\hline L. Derecha mesial & - & - \\
\hline L. Derecha proximal & - & - \\
\hline Longitudinal izquierda & - & - \\
\hline Longitudinal mesial & - & - \\
\hline Longitudinal transversal derecha distal & $2,5 \%$ & - \\
\hline Longitudinal transversal derecha mesial & - & $1,1 \%$ \\
\hline Longitudinal transversal derecha proximal & - & - \\
\hline Longitudinal transversal izquierda distal & - & $1,8 \%$ \\
\hline Longitudinal transversal izquierda mesial & $1,3 \%$ & - \\
\hline Longitudinal transversal izquierda proximal & - & - \\
\hline Longitudinal transversal mesial & - & - \\
\hline Longitudinal transversal mesial distal & $4,1 \%$ & - \\
\hline Longitudinal transversal mesial proximal & - & - \\
\hline Marginal & $14,3 \%$ & $19,1 \%$ \\
\hline Transversal distal & $20,4 \%$ & $31,9 \%$ \\
\hline Transversal distal izquierda & - & - \\
\hline Transversal mesial & $4,1 \%$ & $4,3 \%$ \\
\hline Transversal mesial izquierda & $1,5 \%$ & $3,2 \%$ \\
\hline Transversal proximal & $14,3 \%$ & $2,1 \%$ \\
\hline
\end{tabular}

\ TABLA 4. Distribución de los tipos de fracturas y frecuencia por las materias primas principales. 


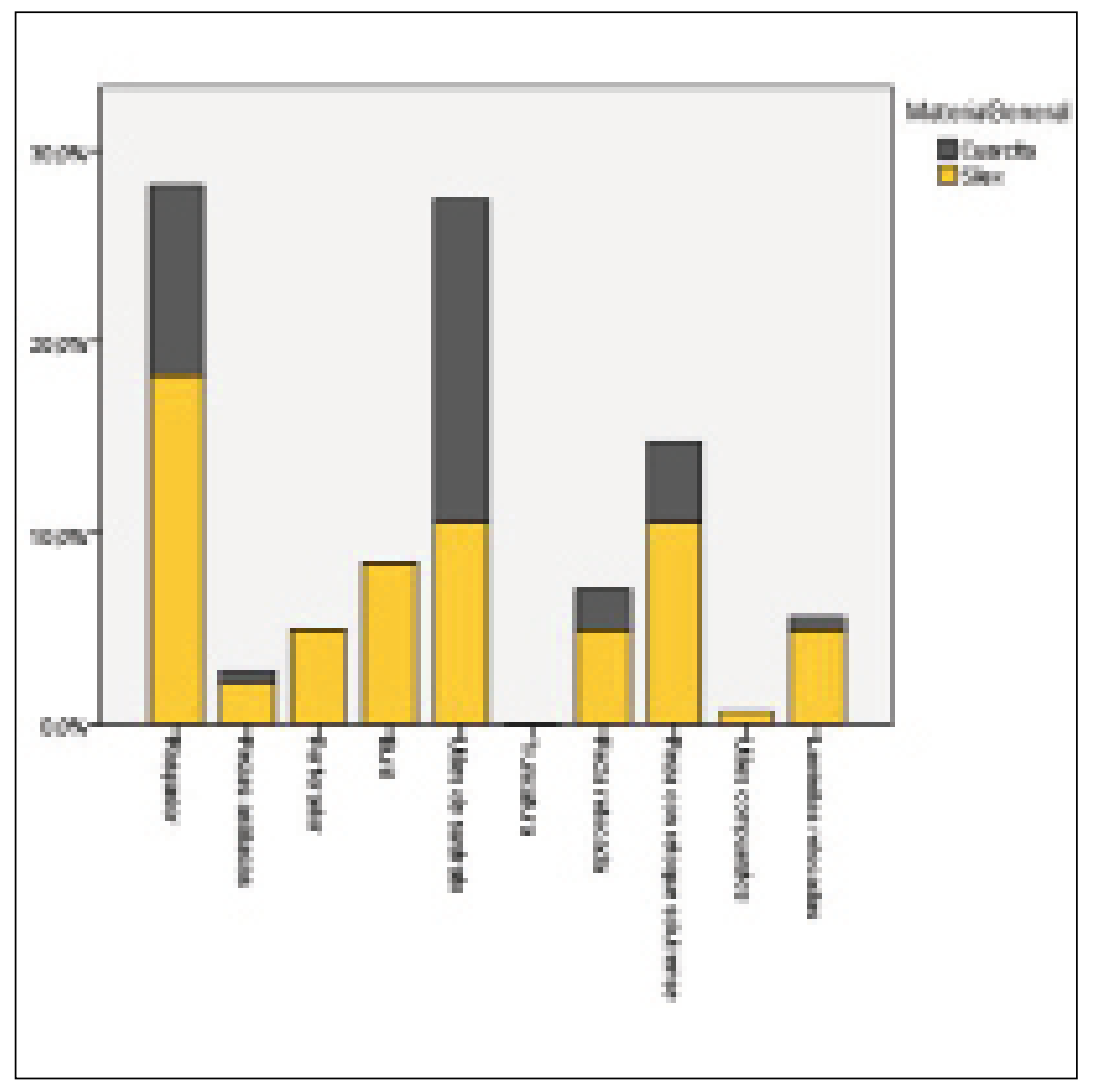

FiguRA 12. Frecuencia de los grupos tipológicos principales $\mathrm{y}$ distribución por materia prima.

vamente de piezas completas o con fractura marginal); pero hay diferencias entre ellas según el tipo de fractura aunque las transversales dominen en ambos conjuntos, dado que el porcentaje de fragmentación proximal en las cuarcitas se invierte con el de la fragmentación distal en las piezas silíceas.

\subsection{Estudio tipológico de los útiles}

La distribución de los útiles del nivel VI del abrigo de La Viña muestra la importancia de los útiles de sustrato o los raspadores y la desigual repartición de la materia prima entre estos grupos. La cuarcita predomina en el utillaje de sustrato y tiene una proporción aceptable entre los raspadores y los útiles típicamente solutrenses, mientras que el sílex es prioritario entre los buriles, los perforadores y las laminillas (Fig. 12).

\subsubsection{Raspadores}

Dentro de este grupo (Figs. 13 y 14) hay trece subtipos distintos, siendo entre ellos dominantes los raspadores simples sobre lasca o lámina, seguidos de los raspadores carenados (incluyendo los atípicos), representando ambos tipos más del $65 \%$, y después tienen cierta significación los raspadores sobre lasca o lámina retocadas, y el resto no alcanza el 5\% de los ejemplares. En lo que hace a la materia prima, estas piezas sólo se elaboran sobre cuarcita y sílex, existiendo una dedicación preferencial de la cuarcita a los grupos numerosos, salvo en el caso de los dos ejemplos de raspador en abanico.
Por otro lado se constata un dominio muy marcado de los soportes de tipo lasca, sobre los que se realiza un 81,3\% de los raspadores documentándose el 16,3\% como láminas. Debe hacerse constar que los tres ejemplos de raspadores unguiformes se realizan en una lasca de menos de $25 \mathrm{~mm}$ y en dos laminillas, siendo estos tres los únicos soportes de formato pequeño y que caracterizan juntos ese $2,4 \%$ restante. Resultan especialmente interesantes ya que estos raspadores de formato unguiforme suponen un tipo muy frecuente del Solutrense medio y superior cantábrico.

\subsubsection{Perforadores}

Confeccionados todos sobre productos de lascado se reparten de manera equitativa entre lascas y láminas, contándose seis ejemplares en cada formato. En lo que hace a la materia prima todos ellos se realizan en sílex y curiosamente, la mayor parte de ellos en la variedad de Piedramuelle.

\subsubsection{Buriles}

Dentro de este grupo se han documentado diferentes tipologías, sobresaliendo entre ellas los buriles diedros de ángulo, que suponen casi un 35\% de los ejemplos. Los buriles de ángulo sobre rotura le siguen en importancia. Finalmente el resto de tipos no superan los cinco ejemplares y son: buriles múltiples (sobre truncatura retocada, diedros y mixtos); buriles sobre truncatura retocada (convexa y cóncava); y finalmente buril plano, con un solo ejemplar. 


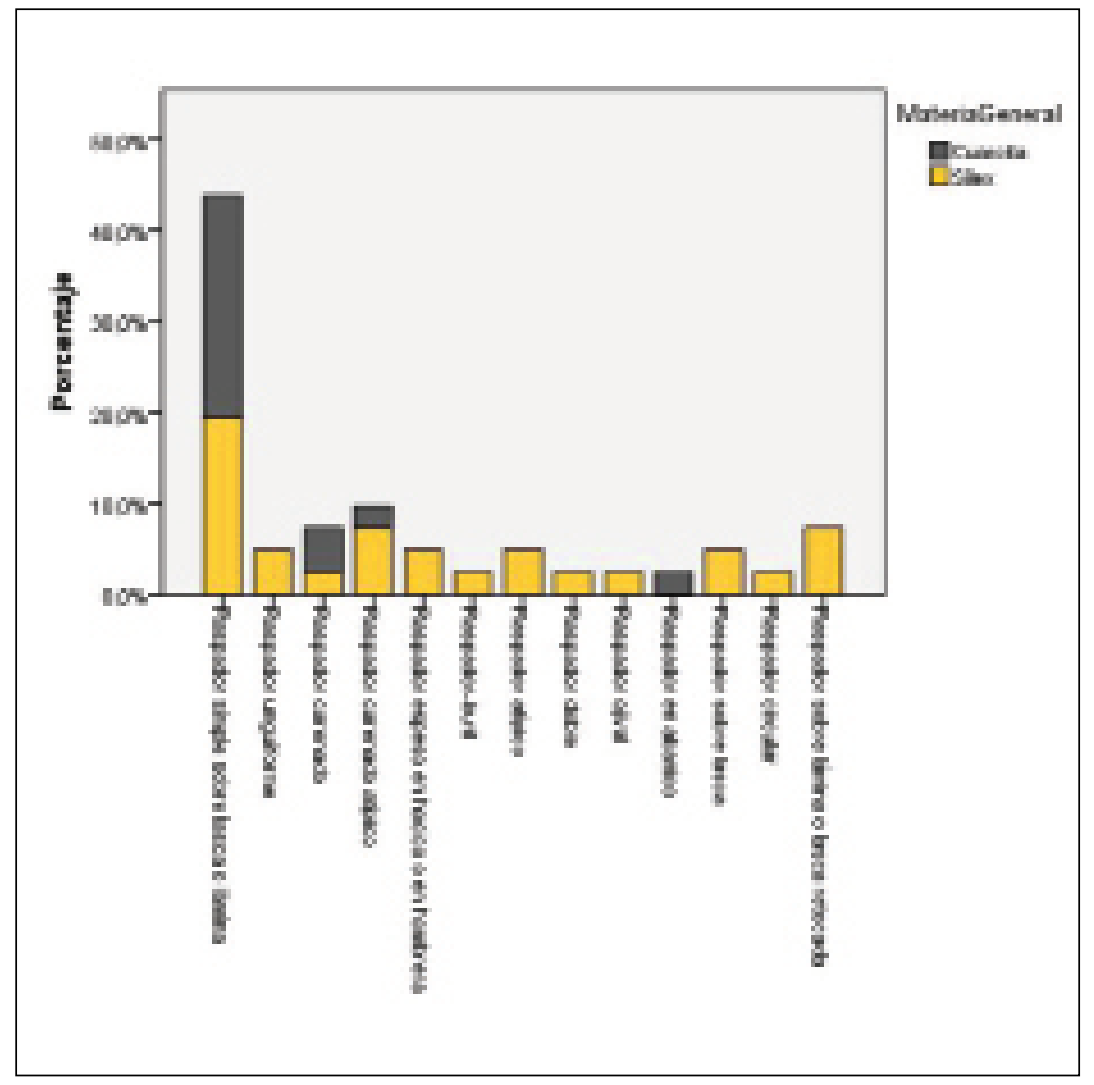

4 Figura 13. Frecuencia de los subtipos de raspadores y distribución por materia prima.

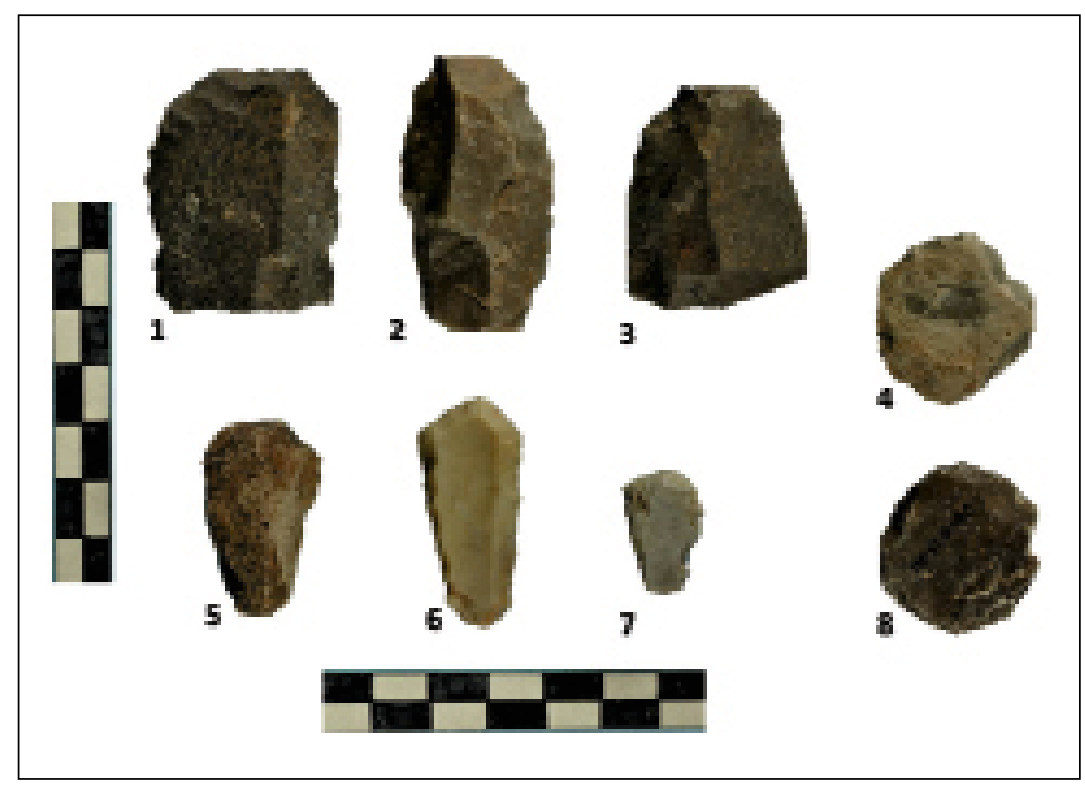

4 Figura 14. Raspadores del nivel VI del sector occidental del Abrigo de la Viña. Cuarcita (n. $\left.{ }^{\circ} 1-3\right)$, sílex (n. $\left.{ }^{\circ} 4-8\right)$. Foto J. Fernández de la Vega.

En relación con el tipo de soporte elegido para la confección de buriles, destaca de nuevo el equitativo reparto entre lascas y formatos laminares, contándose entre estas una laminilla en que se realiza uno de los buriles diedros de ángulo. Hay, además, una evidente selección del sílex que es utilizado para realizar todos los buriles siendo más del $50 \%$ de ellos de difícil atribución por su estado de desilificación. La mitad restante se reparte equitativamente entre las variedades de Piloña y Piedramuelle.

\subsection{4 Útiles de sustrato}

Como ya se ha señalado, los elementos denominados de sustrato (Fig. 15) constituyen una de las tipologías más destacadas en el conjunto lítico del nivel VI. Cómo caracterizan Sonneville-Bordes y Perrot (1955), dentro del grupo de sustrato se incluyen básicamente los denticulados (Fig. 16) y las raederas, si bien contamos también con muescas.

Estos elementos se elaboran mayoritariamente en cuarcita que representa más del 60\%. El resto de piezas, reali- 


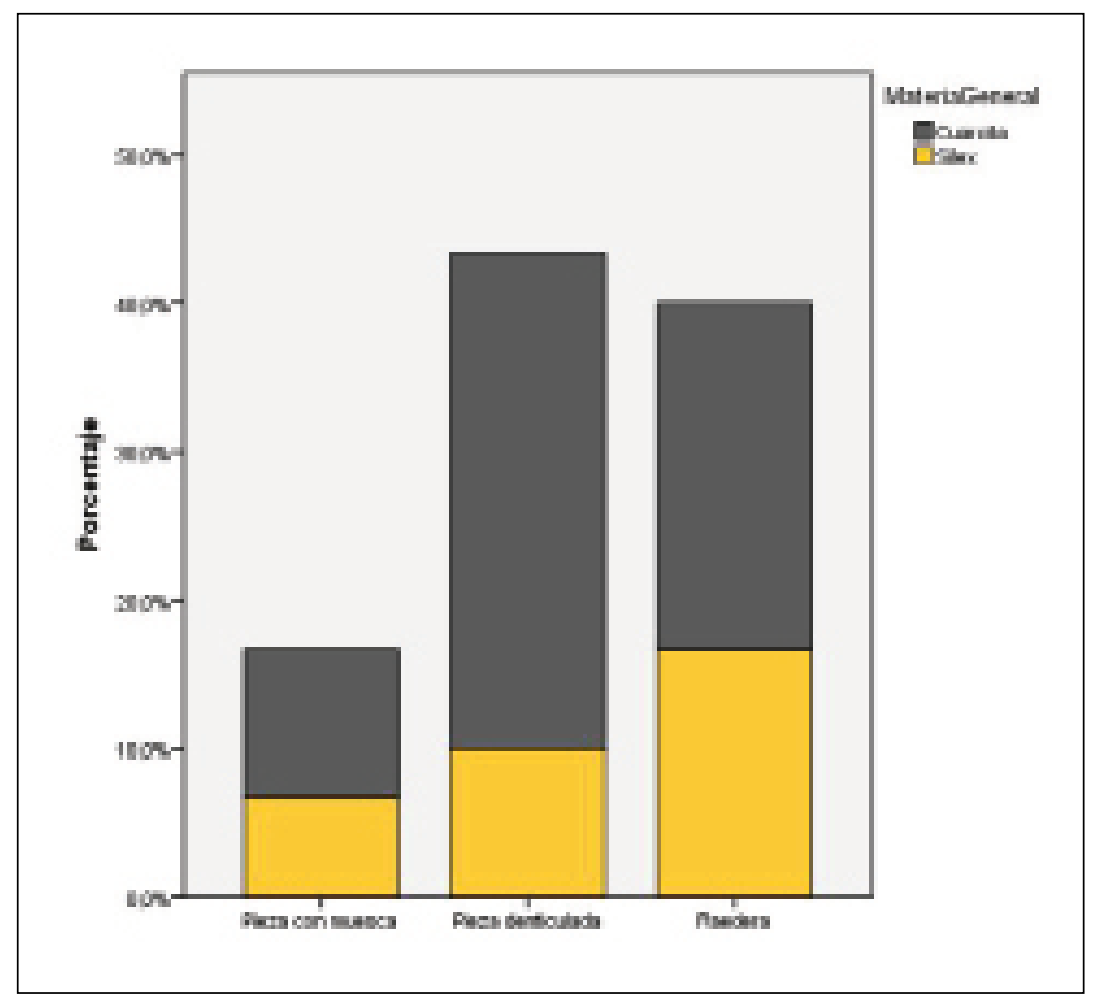

Figura 15. Distribución de los diferentes útiles de sustrato definidos.

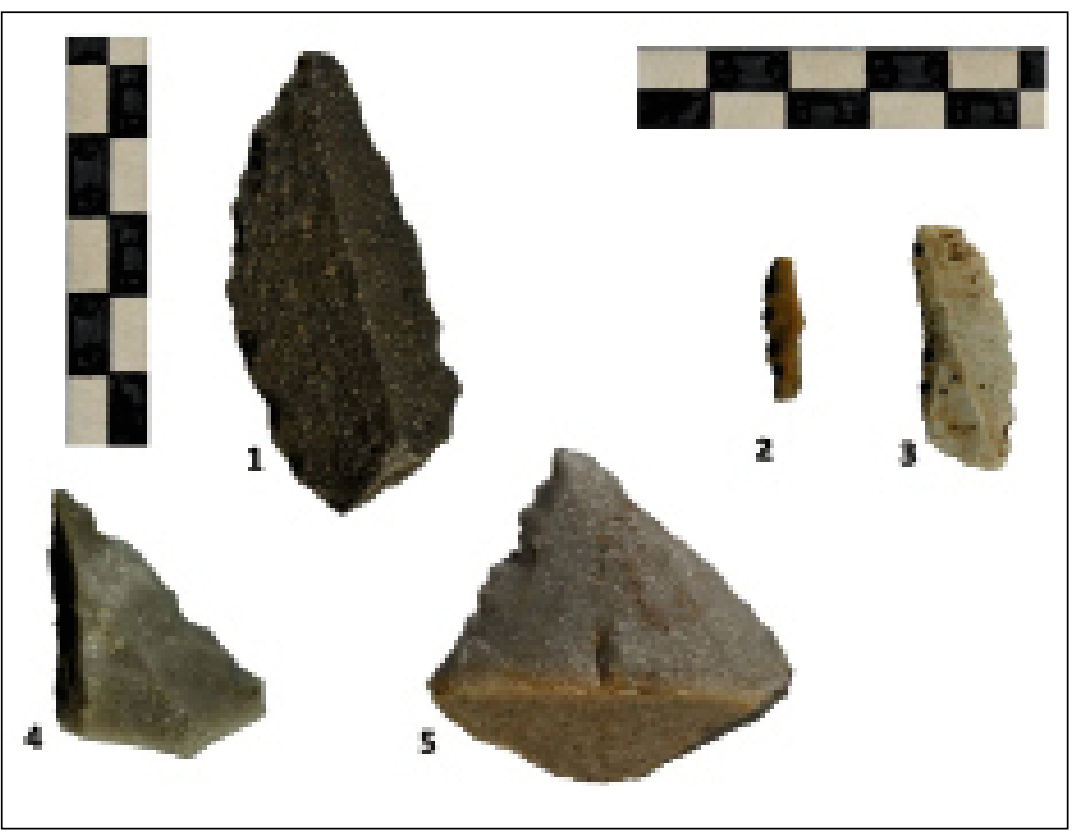

4 Figura 16. Denticulados del nivel VI del sector occidental del Abrigo de la Viña sobre diferentes soportes. Cuarcita (n. $\left.{ }^{\circ} 1,4,5\right)$, sílex (n. ${ }^{\circ} 2$ y 3). Foto J. Fernández de la Vega.

zadas en sílex, se contarian en un 17,9\% en la variedad de Piloña, siendo ya muy bajo el porcentaje en Piedramuelle $(7,6 \%)$ e indeterminado por su desilificación el 10\% restante. Cabe señalar la presencia de dos ejemplos de raederas en sílex caliza de montaña. Igualmente resulta curiosa la especial dedicación del sílex de Piloña a las piezas con muesca, donde resulta especialmente mayoritario.

En lo que respecta al tipo de soporte, se opta de manera mayoritaria para realizar estas piezas por las lascas que, incluyendo las de formato inferior a $25 \mathrm{~mm}$, suponen más del 75\% de los útiles. El 23,9\% restante son láminas y solamente 2 útiles se realizan sobre fragmentos diaclásicos. Cabe señalar que, a su vez, todas las raederas se realizan sobre lasca y que las láminas y las lasquitas aparecen tanto en las denticulaciones como en las piezas con muesca, siendo siempre realizadas en sílex las láminas. Igualmente debe hacerse constar que un número elevado de las laminillas del grupo tipológico denominado laminillas retocadas, 

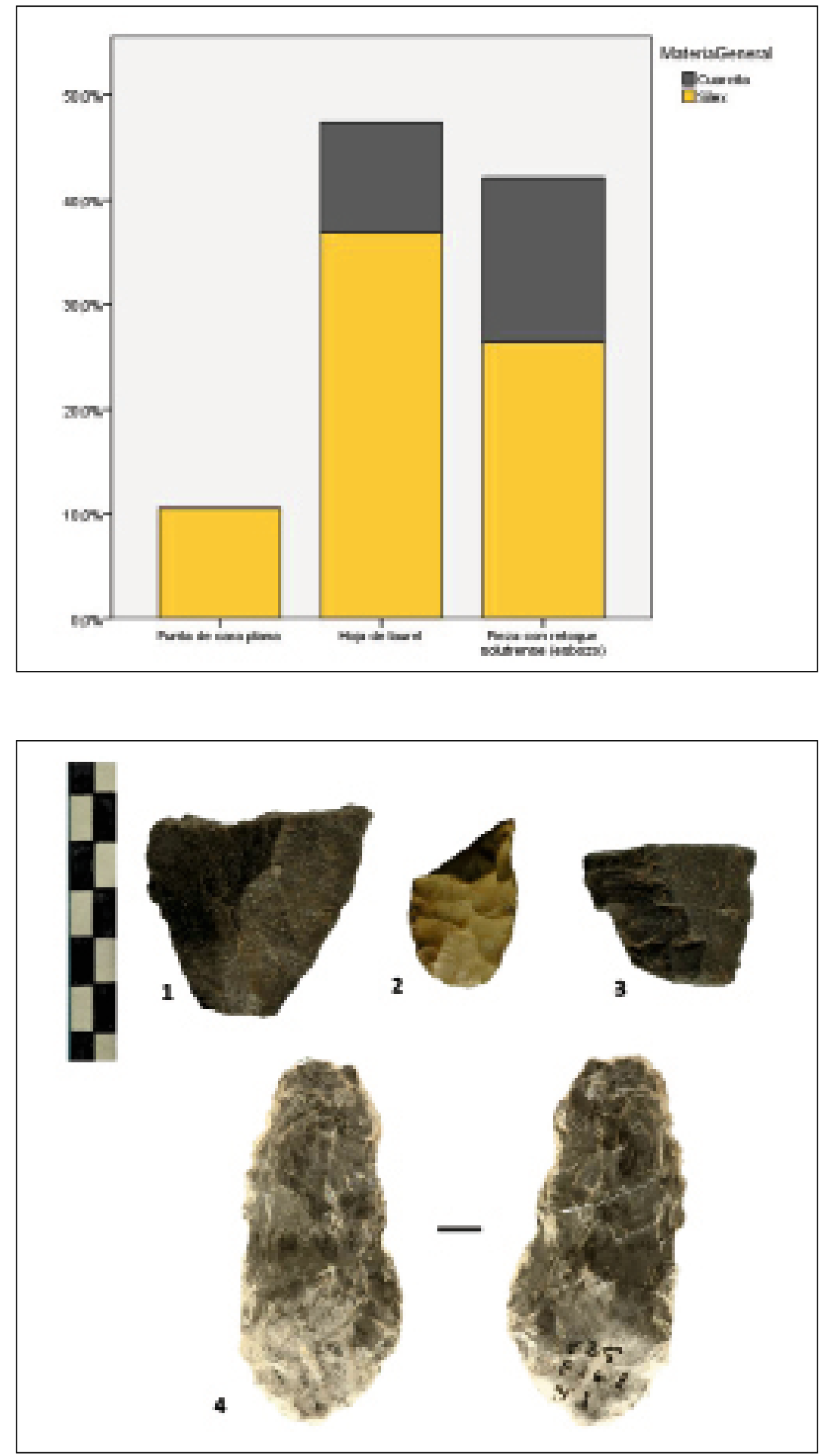

4 FiguRa 17. Frecuencia de los tipos característicos solutrenses recuperados y distribución por materia prima.
4 Figura 18. Ejemplos de fragmentos de "esbozos" Solutrenses en diferentes estados del proceso de fabricación (n. $\left.{ }^{0} 1-3\right)$. Cuarcita (n. $\left.{ }^{\circ} 1,3\right)$, sílex (n. ${ }^{\circ}$ 2). Hoja de laurel realizada en cuarzo hialino (n. $\left.{ }^{\circ} 4\right)$. Foto J. Fernández de la Vega. presentan un retoque de tipo denticulado (casi el 60\%), que las inscribiría de manera quizá más conveniente como ejemplares de formato más reducido de las láminas de este grupo.

La denticulación aparece tanto sobre uno de los laterales como en los dos, tendiendo en estos casos hacia las formas apuntadas, sin llegar a poder encuadrarlo dentro de las características puntas de Tayac, aunque teóricamente se asemeje en su descripción. Igualmente es frecuente la prolongación de la denticulación desde uno de los laterales hasta el extremo distal.

En lo que hace a las raederas todas ellas se elaboran sobre lascas que, en cuarcita, muestran el retoque escamoso propio de estos útiles. Es destacable la presencia discreta de raederas planas, con retoques amplios y continuos en los laterales, típicas de este periodo Solutrense. 


\subsection{5 Útiles solutrenses}

El utillaje solutrense del nivel VI del abrigo de La Viña se reduce a la presencia de puntas de cara de plana y de hojas de laurel (Figs. 17, 18 y 19). Es destacable sin embargo la presencia en número elevado de piezas que, teniendo retoque solutrense, no llegan a adquirir forma de útil terminado, debido generalmente a fracturas involuntarias e inoportunas, y que consideramos como esbozos de útiles solutrenses. Considerando los tipos aludidos, las puntas de cara plana no suponen más que el 10\%, siendo las hojas de laurel el útil más representado.

El sílex es, así mismo, la materia prima dominante en este grupo. Si bien hay notables ejemplos de fabricación de hojas de laurel en cuarcita, así como la ya señalada excepcional pieza en cuarzo hialino. La dificultad técnica que plantea este tipo de útil se revela especialmente complicada para su realización en cuarcita, de manera que no es de extrañar que sea más aparente el porcentaje de cuarcitas dentro del grupo de esbozos o intentos de realización de piezas solutrenses.

Dentro de la materia silícea, que supone casi el 70\% del material empleado en este grupo tipológico, es el silex de Piedramuelle el más representado, pues se realiza en esta materia el $26 \%$ de todos los útiles solutrenses. La variedad de Piloña apenas pasa del 20\%. En un porcentaje similar se mueve el nivel de indeterminados por el estado de desilificación. Finalmente debe señalarse la presencia de una hoja de laurel realizada en la variedad silicea denominada caliza de montaña.

Las puntas de cara plana y los fragmentos de hojas de laurel, bifaciales y de base redondeada, presentan un retoque plano, característicamente solutrense y propio de estas foliáceas, que sin duda caracterizan esta serie lítica. Si bien este retoque plano no es estrictamente paralelo, al igual que ocurre en el cercano yacimiento de Las Caldas (Corchón,
1981), no hay ejemplos claros de retoque regular plano y paralelo que pudiera haber sido realizado sólo por presión.

\section{CONCLUSIONES}

La lasca es el soporte prioritario de las piezas retocadas en el nivel VI del sector occidental de La Viña (59,4\%), sin menoscabo del índice laminar que también tiene su importancia (39\%) con porcentaje muy superior de láminas respecto a laminillas. Como ya sucedía en otros niveles de este yacimiento "... parece haber una preferencia por la selección de lascas para su transformación en útiles que, hipotéticamente, podría estar relacionada con una producción mayoritaria de este tipo de soporte vinculada, a su vez, a los condicionamientos impuestos por el tipo de materia prima predominante en la zona; en este sentido, cabe destacar igualmente el mayor porcentaje de láminas en sílex, cosa lógica por otro lado, pues es un hecho constatado en yacimientos del Paleoliticos superior... En el mismo sentido apunta el estudio estadístico de la longitud, anchura y espesor de los útiles que permite documentar el desarrollo de diferencias significativas en el tamaño de los útiles en función de la materia prima, constatándose unas dimensiones medias superiores en la cuarcita" (Martínez 2010: 181).

En relación con el estudio las fracturas, matizado en principio por la necesidad de evaluar las piezas no retocadas, al no producirse diferencias relevantes según la materia prima, al dominar las fracturas transversales y a la mayor frecuencia de la fracturación de los soportes laminares, este proceso tecnológico puede deberse con mayor probabilidad a causas postdeposicionales o de uso más que a una voluntad expresa previa a su utilización. Si en el futuro el resto de talla mantuviera los mismos patrones que los de los útiles

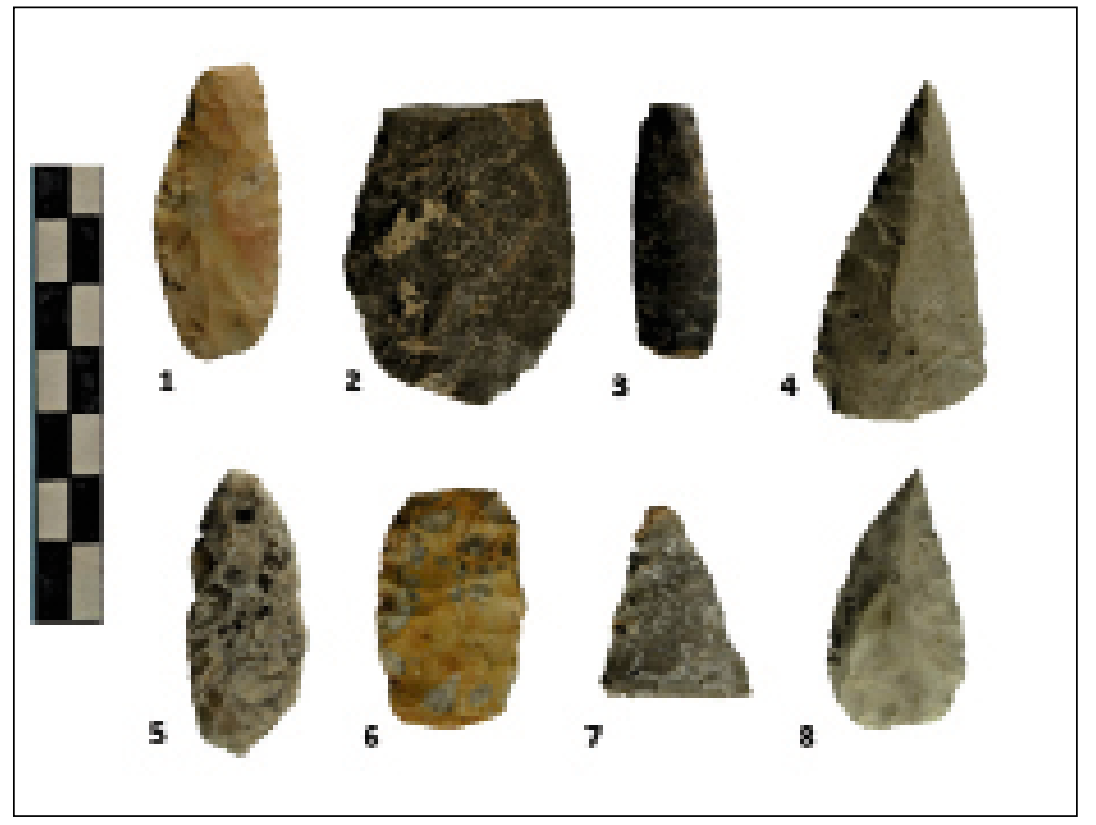

Figura 19. Hojas de laurel (n. $\left.{ }^{\circ} 1-3,5-7\right)$ y puntas de cara plana $\left(n .^{\circ} 4,8\right)$ del nivel VI del sector occidental del Abrigo de la Viña. Cuarcita (n. ${ }^{\circ}$ 2-3), sílex (n. $\left.{ }^{\circ} 1,4-8\right)$. Foto J. Fernández de la Vega. 
se constataría definitivamente la propuesta antes aludida (involuntariedad y causas postdeposicionales); mientras que en caso contrario habría que acogerse al factor antrópico como desencadenante de esa otra realidad.

La posición en estratigrafía del nivel VI del sector occidental de La Viña, entre un Solutrense superior (niv. V) y otro Gravetiense (niv. VII), y la presencia de piezas tan privativas como las puntas de cara plana y las hojas de laurel, hacen muy plausible su adscripción al Solutrense medio (Fortea 1992, 1995). Fortea (1992) que señala este solutrense es equivalente al Solutrense medio descrito por Corchón (1981) en el cercano yacimiento de Las Caldas. Esas coincidencias se establecen, entre otras cosas, con las características hojas de laurel bifaciales de base redondeada y las puntas de cara plana adquieren en ambos yacimientos unas formas tipométricas y tipológicas muy similares, que sin duda las hermanan.

En lo que hace a la materia prima las similitudes son también notables hasta el punto de reproducirse en ambos yacimientos unas excepcionales hojas de laurel completas, bifaciales y de base redondeada delicadamente talladas en cristal de roca. Incluso, si atendemos a los inventarios tipológicos (Corchón 1981) publicados en el nivel 14 de la Sala I pese a presentar 59 útiles se observa una organización tipológica que concuerda genéricamente con lo expuesto en este estudio, de tal manera que nos encontramos similares tipos de raederas; buriles diedros y múltiples; puntas de cara plana y hojas de laurel; denticulados, raederas y piezas astilladas; y piezas con retoque continuo en uno o ambos bordes. Por su lado, en los niveles 12 y 15 de la secuencia del Pasillo de Las Caldas los inventarios tipológicos (Corchón 1981) muestran una mayor similitud con este nivel de La Viña que los de la Sala I. Cabe señalar entre dicha similitud la correlación en el porcentaje lascas-láminas que, en Las Caldas al igual en La Viña, se sitúa en torno a un $60 \%$ de lascas.
Todo esto nos lleva a corroborar la relación que Fortea establecía entre este Solutrense medio de Las Caldas, originariamente llamado Solutrense medio típico o $A$, y el nivel VI del sector occidental de La Viña. No obstante cabe introducir en la valoración la presencia de ciertas diferencias que, si bien no merman la atribución cultural indicada, sí nos ayudan a precisar sus caracteres. Así pues, en el caso de la materia prima, Las Caldas presenta un uso mucho más mayoritario del silex que La Viña (respectivamente un 80\% frente a un 65\%). Otra diferencia importante afecta al reparto del utillaje entre los grupos tipológicos: así, los inventarios tipológicos de Las Caldas presentan para este periodo una representación amplia de buriles, mayor que en nuestro estudio y un índice netamente inferior de raspadores y elementos de sustrato. Como hemos expuesto, estas variables adquieren en La Viña proporciones totalmente diferentes, lo cual no deja de ser interesante pues, a la vez que se distancia de lo observado en Las Caldas, hace a este yacimiento mucho más acorde a las colecciones del Solutrense medio típico del suroeste francés.

El estudio que nos ocupa ha reforzado la adscripción cultural del conjunto y reafirmado la atribución del nivel VI al Solutrense medio. De esta manera contamos con útiles directores clave como resultan las puntas de cara plana y las hojas solutrenses, piezas foliáceas de retoque típicamente solutrense y formato propio del periodo medio. Pero de igual manera contamos con un registro lítico que en proporciones se asemeja a las colecciones de referencia del suroeste francés, a la vez que presenta útiles asociados de manera habitual a este periodo como son los raspadores unguiformes y las raederas tan frecuentes en el Solutrense medio de Las Caldas. Además tenemos evidencias de una selección de materias primas y de los tipos de soporte destinados a la confección de los útiles. Y, finalmente, esta aportación se completará con el análisis del resto de talla y el pertinente estudio traceológico. •

\section{BIBLIOGRAFÍA}

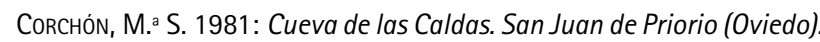
Ministerio de Cultura. Madrid.

- 1992: "La Cueva de Las Caldas (Priorio, Oviedo) II. Investigaciones efectuadas entre 1987 y 1990". Excavaciones Arqueológicas en Asturias 1. Principado de Asturias. Oviedo: 33-47.

- 1999a: "La Cueva de Las Caldas (Priorio, Oviedo) IV. Investigaciones efectuadas entre 1995 y 1998". Excavaciones Arqueológicas en Asturias 4. Principado de Asturias. Oviedo: 43-57.

- 1999b: "Solutrense y Magdaleniense del oeste de la cornisa cantábrica. Dataciones calibradas y marco cronológico". Zephyrvs, 52: 3-32.

Duarte, E., Santamaria, D., Rasilla, M. De La, Martinez, L., Fernández De la Vega, J, SuÁrez, P. y TARRIÑo, A. 2011: "El sílex como recurso mineral en la Prehistoria de Asturias". Workshop Silex: trazadores litológicos de larga distancia durante la Prehistoria de la Península Ibérica. Burgos. En prensa.
Fortea PéReZ, J. 1990: "Abrigo de la Viña. Informe de las campañas 1980-1986". Excavaciones Arqueológicas en Asturias 1980-1986 1. Principado de Asturias. Oviedo: 55-68.

- 1992: "Abrigo de la Viña. Informe de las campañas 1987-1990". Excavaciones Arqueológicas en Asturias 1987-1990 2. Principado de Asturias. Oviedo: 19-28.

- 1995: "Abrigo de la Viña. Informe y primera valoración de las campañas 1991-1994". Excavaciones Arqueológicas en Asturias 19911994 3. Principado de Asturias. Oviedo: 19-32.

- 1999: "Abrigo de la Viña. Informe y primera valoración de las campañas 1995-1998". Excavaciones Arqueológicas en Asturias 19951998 4. Principado de Asturias. Oviedo: 31-41.

Fortea, J., Rasillia, M. De La; Martinez, E., Sánchez-Moral, S., Cañaveras, J. C., Cuezva, S., Rosas, A., Soler, V., Juliá, R., De Torres, T., Ortiz, J. E., CAStro, J., BAdAl, E., Altuna, J. y Alonso, J. 2003: "La Cueva de El Sidrón (Borines, Piloña Asturias): Primeros resultados". Estudios Geológicos 59: 159-179. 
Fortea, J., Rasilla, M. De La, Santamaria, D., Martinez, L., Martinez, E., Cañaveras, J. C., Sánchez, S., Cuezva, S., Muñoz, M. C., Fernández, A., Rosas, A., BastiR, M., Huguet, R., Garcia, A., Estalricich, A., Garcia, S., Fernández, B., Sesé, C., Lalueza, C., Silva, P. G., Santos, G., Carrasco, P., Huerta, P. y TarRiño, A. 2009: "Cueva de El Sidrón (Borines, Piloña, Asturias)". Informe sobre la campaña arqueológica de 2009. Consejería de Cultura y Turismo, Principado de Asturias. Oviedo.

Fortea, J., Rasilla, M. de la, Santamaría, D., Martinez, L., Duarte, E. y FerNÁNDEZ DE LA VEGA, J. 2010: "El Paleolítico superior en Asturias en los albores del siglo XXI". En X. Mangano (ed.): El Paleolitico superior peninsular. Novedades del s. XXI. Monografies 8. SERP. Barcelona: 271-289.

Martinez, L. 2010: Estudio tecno-tipológico y tafonómico de las industrias líticas de final del Auriñaciense y comienzo del Gravetiense en el Abrigo de La Viña (La Manzaneda, Oviedo). DEA. Facultad de Filosofía y Letras. Universidad de Zaragoza.

SANTAMARIA, D. 2006: Clasificación y estudio de los materiales musterienses de la cueva de EI Sidrón. Trabajo de investigación. Universidad de Oviedo.

- 2012: La transición del Paleolítico medio al Paleolítico superior en Asturias: el abrigo de La Viña y la cueva de El Sidrón. Tesis Doctoral. Universidad de Oviedo.

Santamaria, D., Fortea, J., Rasillia, M. De La, Martinez, L., Canaveras, J. C., Sanchez- Moral, S., Rosas, A., Estalrrich, A., Garcia- Tabernero, A. y LaLUEZA- FoX, C. 2010: "The technological an typological behaviour of a Neanderthal group from El Sidrón Cave (Asturias, Spain)". Oxford Journal of Archaeology 29 (2): 119-148.
Santamaría, D., Rasilla, M. De La, Martínez, L. y Tarriño, A. 2011: "Las herramientas y su interpretación cultural y económica". En M. de la Rasilla, A. Rosas, J. C. Cañaveras, C. Lalueza-Fox, C. (eds.): La cueva de El Sidrón (Borines, Piloña, Asturias) Investigación interdisciplinar de un grupo neandertal. Excavaciones Arqueológicas en Asturias. Monografias I: 137-146.

SonnevilLe-Bordes, D. DE y PerRot, J. 1954: "Lexique typologique du Paléolithique supérieur". Bulletin de la Société Préhistorique Française 51 (7): 327-335

- 1955: "Lexique typologique du Paléolithique supérieur. Outillage lithique III -outils composites- perçoirs". Bulletin de la Société Préhistorique Française 52 (1): 76-79.

- 1956: "Lexique typologique du Paléolithique supérieur". Bulletin de la Société Préhistorique Française 53 (7): 408-412.

- 1956b: "Lexique typologique du Paléolithique supérieur". Bulletin de la Société Préhistorique Française 53 (9): 547-559.

SUÁREZ, P: "Definición tecno-tipológica y funcional de las laminillas Dufour: el caso de los niveles IX y VIII del Sector Central del Abrigo de La Viña (La Manzaneda, Oviedo, Asturias)". CKQ, 2. En prensa.

Tarriño Vinagre, A., Duarte Matias, E., Santamaria Álvarez, D., Martinez Fernández, L., Fernández de la Vega Medina, J., Suárez Ferruelo, P., Rodriguez Otero, V., Forcelledo Arena, E. y Rasilla Vives, M. De La. 2012: "El sílex de Piloña. Caracterización de una nueva fuente de materia prima en la Prehistoria de Asturias". F. Javier Fortea Pérez. Universitatis Ovetensis Magister. Universidad de Oviedo y Ménsula Ediciones. Oviedo. En prensa. 